\title{
Communication \\ The Challenges for Gender Equity and Women in Leadership in a Distributed University in Regional Australia
}

\author{
Janelle Thomas ${ }^{1}$, Cate Thomas ${ }^{1, *(\mathbb{D})}$ and Kirsty Smith ${ }^{2}$ \\ 1 Faculty of Science, Charles Sturt University, Wagga Wagga, NSW 2678, Australia; janethomas@csu.edu.au \\ 2 Faculty of Science, Charles Sturt University, Bathurst, NSW 2795, Australia; kirssmith@csu.edu.au \\ * Correspondence: cthomas@csu.edu.au; Tel.: +61-2-6933-2398
}

Received: 27 March 2019; Accepted: 24 May 2019; Published: 30 May 2019

\begin{abstract}
The barriers to women's achievement and career progression in the higher education sector have been well researched. It has long been acknowledged that career breaks for child-rearing, and women's self-beliefs about their abilities can impact negatively on their careers, and many programs and policies have been implemented to redress these around the world. This article is focussed around a regional Australian university, with multiple campuses distributed over $1000 \mathrm{~km}$ across two states. Courses, schools, and work teams are often spread across multiple campuses, and travel between campuses is sometimes a necessity; one that is time-consuming and requires time away from family. For some women, travelling is not possible due to family and other commitments or constraints. This paper explores how working in a regional university, with distributed campuses, has an additional impact on women's career progression. Through auto-ethnographic accounts of four female staff members, we explore the intersection of gender and location through case studies of personal experiences, investigating the effects that distance and travel limitations can have on participation in work team and networking events, access to professional development opportunities, and career progression within the institution.
\end{abstract}

Keywords: gender equity; distributed university; case study; career progression; women; distance; work travel; intersectionality

\section{Introduction}

This paper is based on the experiences and reflections of four female university staff upon their journey and involvement in the institution-wide self-assessment process undertaken in applying for a Bronze Institutional Award in the Athena SWAN (Scientific Women's Academic Network) gender equity charter. This process assisted in the raising and clarifying of new and different barriers that impact on women's achievements, providing the opportunity to reflect on these issues and consider ways to address them and make improvements.

It became apparent through the Athena SWAN self-assessment process that there were significant similarities to previous research in terms of key experiences, policies, and procedures in redressing gender equity for women at the University (David 2015; Kim 2011; Neale and White 2014; Probert 1998; Silander et al. 2013; Wasserman 2017). The impact of neoliberal progression, capitalization, and entrepreneurship of the education sector, as outlined in Blackmore (2013), has also flagged both academic and student dissatisfaction in the homogenization of the sector, and further, the impact this has had when considering a gendered lens. David (2015) research highlights more of a gendered balance in higher education, particularly of student and first in family cohorts to attend university, however, there is still a place to explore and to achieve genuine gender equity for female academics. 
There are numerous accounts within the current study suggesting that these women face common barriers when exploring notions of gender equity in the workplace such as salary, career progression, and seniority, together with similarities of gender barriers and divides as reported in the higher education field (Allan 2008; Allen et al. 2006; Probert 1998; The Associated Press 2010). It also became evident through the Athena SWAN process that there were significant distinctions and uniqueness of experiences for these women. The focus of this study was these differences; the uniqueness of geography and place, and the impact of these intersectionalities, in addition to those barriers already identified (Griffin and Museus 2011). A self-reflective methodology and account was undertaken, which considered the contrasts of not only regional geography, but vastly distanced distributed campuses that signified further layers of complexity for women striving for and delivering strategies for gender equity.

This paper explores key themes including current barriers for women in regional locations moving into higher education leadership (including recruitment, promotion, and retention); the impact of diversity measures such as Athena SWAN and a lens of intersectionality; and reflections from women about their careers. Key considerations of the study included a focus on fixing the organisation, not fixing the women, as addressed by Burkinshaw and White (2017), and the impact of organisational and business delivery structures, policy, and procedures. Further concepts explored included the progression of pay equity; ability-based recruitment and promotion, where the University considers achievement relative to opportunity (as opposed to time served) (Winchester et al. 2006); and not being a workplace that prizes 'male' attributes over 'female' attributes as progressive steps to enabling gender equity. By these steps, the University is breaking the culture of the glass ceiling and the traditional patriarchal systems (Morley 2014; Redmond et al. 2017). Instead, the University is providing pathways and enabling programs to assist women who aspire to be educational leaders to achieve such.

This study was undertaken not only to understand the barriers to gender equity in higher education institutions, but to raise conversation and provide insight around how female employees of a regional university with distributed campuses may face additional barriers to gender equity. The study has resulted in a commentary that can be further developed and used for contrast and comparison for other higher education providers in Australia and beyond.

\section{Methods}

This study was undertaken using an inductive approach, based on the observations of four female University staff members about barriers to gender equity within their place of work and working in a distributed campus model. Participants (denoted P1 to P4 for quotes) were provided with a set of questions to use as prompts for auto-ethnographic exploration (Denshire 2014; Shaw and Gould 2001a, 2001b; Tomaselli 2013) based on critical reflection of their circumstances, experiences, and situations within the University. Purposive sampling (Alston and Bowles 2018) was used to select the four participants from the Self-Assessment Team who participated in the Athena SWAN application process. This type of sampling was utilised to ensure a cross-functional view of participants at the University could be explored, that is, a mix of differing career classifications, locations, carer responsibilities, and other intersectionalities to elicit (or not) whether there were common or similar factors that impacted firstly on engaging with their work, and secondly looking forward to progression.

Each participant was provided with the questions via email and asked to consider the questions and provide a written response discussing how each question impacted on them. The questions were as follows:

- Describe your work team/s (past and present, if relevant) and your relationships within the team.

- Working at the University often requires travel, how easy do you find it to travel given your personal circumstances?

- How has travel (or the inability to travel) affected your access to professional development and other opportunities, e.g., training, conferences etc.? 
- Has the composition and location of your work team affected your ability to participate in events? What impact does this have on working relationships?

- What impact has the intersection of gender, personal circumstances, travel, access to professional development/other opportunities and team events had on your career progression?

- Do you feel the terms of your employment (fraction, employment/contract-type) have impacted on your career progression?

- Do you have any suggestions to reduce these barriers at the University?

These questions were prompts for self-reflection, and follow-up was undertaken with participants to firstly either embellish elaborate upon or clarify responses and secondly to add further points for consideration post writing the statement. Transcripts were then coded and thematically analysed (Boyatzis 1998; Galanis 2018) using NVivo 11 (QSR International Pty Ltd, Melbourne, Australia) in order to identify common factors that were either barriers or enablers to improving gender equity within the University.

Participants (age range 39-53) were from a combination of academic and professional streams, and STEM (Science, Technology, Engineering, Mathematics)/non-STEM backgrounds. Other intersectionalities of participants included having children or carer responsibilities, identifying as same sex, and having a disability-all of which added to the richness of resulting themes.

\section{Results}

Four female staff members from the University provided critical reflections on their workplace experiences around the intersection of gender, personal circumstances, and travel, particularly focussing on barriers or enablers to gender equity in the context of a regional university with distributed campuses. From this study, four key themes emerged. The following is the exploration of these key themes, which were identified as barriers, together with participants' reflections on potential approaches to reducing these barriers.

\subsection{Travel Limitations and the Need for Planning}

The distributed nature of the University's campuses dictate that travel times of several hours are often needed to attend events face-to-face, including meetings, professional development and other training opportunities. It is a requirement in many position descriptions. Participants with carer responsibilities identified numerous barriers to travel, for example, the participant who was breastfeeding whilst at work noted being very limited, having to either take the child and a carer with them, or not travel at all. The need to plan ahead for travel was a key theme, both for those with carer responsibilities, and disability. Travel necessitated putting in place support mechanisms including carers, working around family schedules, and factoring in recovery time after long journeys. These work-arounds also led to flow-on effects, including having to pay personally to have a carer present, and coping with the emotional strain of being away from family, particularly young children, in order to travel.

Participants noted inflexibility around the scheduling of meetings, professional development and training events. This included insisting on face-to-face meetings, and scheduling events at times which clashed with carers' responsibilities, including early or late in the day, or during school holidays, as well as holding key face-to-face training events on only one campus, necessitating travel to attend. This inflexibility often led to participants not being able to attend, and missing out on valuable opportunities. For example:

“... there is a five year period in my career where I didn't attend a single conference nor did I access any professional development that required travel at all, and that was something that I really just had to kind of do because that was the phase of my life that I was in ... " P4

"There are specific training programs here, held up as the solution for increasing women's leadership capacity, that required overnight travel." P1 


\subsection{Isolation, Disconnection, and Barriers to Network Building}

It is common at the University for courses, schools, and work teams to be spread across multiple campuses. Cross-campus teams hence often meet remotely by talking over the phone or participating in teleconference meetings. This remoteness leads to isolation, reduced spontaneity of interactions, and a lack of personal and social connection. It can also hinder developing real connections with peers and supervisors. It can result in reduced team building and innovation, and also prevents people from providing the day-to-day support often seen among colleagues working in the same physical location. This issue is exemplified by the following quotes:

"I've 'worked with' many people across the University, yet I still have not met most of them in person. Lacking that personal, social interaction means relationships don't go deeper than the professional interaction, and can often be forgotten." P1

"It can be hard to establish relationships or rapport with colleagues or other university stakeholders without that face-to-face contact." P3

"... you absolutely are able to achieve so much more, and we know this, in a ten minute conversation face-to-face than you ever can through five hundred emails. So it certainly does have a big impact on working relationships, particularly when you are trying to form those relationships." P4

The regional location of the University and the necessity to travel also presents a barrier to network building and establishing collaborations with colleagues from other institutions in the sector, particularly for academic staff. Many conferences are held in capital cities, or overseas, necessitating sometimes lengthy travel to attend such fora to present research findings, network, and establish collaborations. Similarly, the lack of geographical proximity to other universities, as is the case in metropolitan settings, presents a barrier to attending other institutions for key meetings and seminars. Further on this theme, travel limitations present a real barrier to building and maintaining international standing and influence in academic areas of expertise. A flow-on effect of this is difficulty in demonstrating impact for promotions applications. The following quotes add depth to this theme:

“... it's a problem for everyone who has children or caring responsibilities, but it's even more of a problem once you geographically isolate yourself. To actually travel and get out and set up those new collaborations or present your research findings ... this [barrier] is far more pronounced for anyone working at a regional university." P4

"It is very difficult to travel to conferences, due both to personal circumstances and working regionally. Travel to domestic conferences usually requires at least a few days away from home as they're mostly in capital cities. International conferences are even more difficult and I have had to turn down offers to present at conferences because of my carer responsibilities." P3

\subsection{Limited Job Security and Training Opportunities}

A key theme, particularly for participants employed in the professional stream, is a lack of job security, which stems from rolling short-term contracts that do not lead to permanent appointments, and a lack of communication around continuity of employment. Whilst this lack of employment security is not an uncommon situation in the higher education sector, the intersectionality of distance and travel contributes to and exacerbates this issue. Due to the distributed nature of campuses, available roles are also distributed across the nine campuses, hence limiting the number of opportunities at any one campus. This limits the potential feasibility of moving from role to role within the university because of constraints on travel or proximity to campuses, as exemplified by this quote:

"As someone on short-term contract after short-term contract, employed in a professional role, with limited ability to travel there are opportunities I don't have access to." P1 
Participants also highlighted that there can be rigid definitions around opportunities for training, which impact on career progression. For example, specific training events may only be eligible to specific position definitions, such as academic staff, or those on continuing contracts, despite being directly relevant to some roles. These definitions can be limiting, for example:

"Over the last couple of years, these definitions have seen me excluded from training in grant writing; leadership development and change management; all skills required in my current role." P1

\subsection{Career Development and Promotion}

The theme of promotion relative to opportunity was important for the two participants from the academic stream, and is key to two intersectionalities of these participants: carer responsibilities and disability, both of which have had an impact on career development and promotion:

"... unless you get promoted to the professoriate before you have children, you really significantly disadvantage yourself, and that's just the reality. It's not to say that you can't do it, but if I look at all the males that did PhDs at the same time as me, we are now at least five or ten years apart in terms of stepping through the different levels inside an academic career. So I have absolutely no doubt that this has a huge impact on career progression." P4

"... intersectionality has impacted on my opportunities to progress research as an early career researcher, and ultimately I changed to teaching professional as I knew I was unable to maintain the research momentum." P2

The University has recently made 'achievement relative to opportunity' a key part of the promotions application process for academic staff, which is a positive step towards improving equity in promotion. Participants have noted the value of women in particular having conversations around it being both acceptable and important to use this section, and being honest about how personal circumstances and intersectionalities have impacted career progress. What are highlighted above are real risks that the participants perceive in terms of career progression. Certain roles or intersectionalities are perceived to inhibit career prospects, and the notion that research within work allocation/function is more prized. This is not to imply that those on teaching professional workload allocation are not successful at progression, however, it is the perception that needs to be further unpacked to enable success and be reaffirmed through policy statement and leadership modelling.

A second theme which emerged around career progression was that there are no promotion opportunities for professional staff, who are not employed in the academic stream.

"There is no promotion process for professional staff; I need to find a new job to be able to progress.

New roles are dependent on an existing role becoming vacant, or another short-term role is created for yet another project." P1

This issue feeds back to the theme of poor job security, and the limitations imposed by available positions being distributed across the campuses. Again, the intersectionality of carer responsibilities and flow-on travel restrictions come into play for these women.

\subsection{Reducing These Barriers at the University}

The University is implementing overarching strategies and initiatives to drive positive change, through its commitment to the Athena SWAN charter and development of the Workplace Gender Equity Strategy 2018-2022. Despite the existence of numerous challenges around career progression for women at a regional university, participants also provided very positive insight into how to potentially reduce these barriers in order to provide a more equitable workplace moving forward.

The theme of challenging long-standing organisational cultural beliefs was key, particularly in regard to workplace flexibility and addressing advancement 'relative to opportunity'; as was ensuring 
senior managers are genuinely engaged with gender and intersectionality issues, particularly in the context of a dispersed workplace. Specific suggestions to implement more flexible workplace practices included having senior managers acknowledge and consider people's responsibilities outside the workplace, particularly around meetings and training opportunities, as well as implementing practices to ensure that career advancement 'relative to opportunity' is recognised and taken into account, especially around promotions. These themes are exemplified by the following quotes:

"Make sure senior leaders are genuinely aware and understanding of the conflicting responsibilities/time pressures of people with carer responsibilities." P3

“... provide staff with flexibility around meeting times/attendance at events." P3

"Certain accommodation such as video conferencing needs to be acceptable rather than stating everyone must be there face-to-face ... it needs to be planned and agreed." P2

"... have a greater acceptance of 'success relative to opportunity' that it should be encouraging all no matter what their individual issues are to progress with research at a pace that is mutually acceptable." P2

"Staff who have been employed continuously, despite each contract being for short periods e.g., 1-2 years, should be recognised and treated as continuing staff in terms of access to training." P1

\section{Discussion}

The four auto-ethnographies presented bring a richness of insight into how women engage with careers in the higher education environment and equally identifies those barriers that are relevant to physical localities, establishments, systems, and negative impacts on opportunity. The mere physical location of the University brings some complexities that perhaps metropolitan counterparts may not experience. Being rural and regional signifies impacts on time and travel for professional development, training, and the carrying out of work duties. These additional intersectionalities can influence work satisfaction and accomplishment, and can be limiting in the context of carer responsibilities that may not allow nor enable access to travel and training opportunities. The impact of geographical distance and disconnection impacts significantly on women who wish to progress in their careers. The sense of lost networks, isolation, and general confidence levels of the study participants to progress was clearly articulated. Further to this was the theme of broader disconnection to team, such as the inability to collaborate, the constraints on opportunities for incidental or informal discussions, the sharing of ideas, or having the 'water cooler conversations' that may provide the seed for the next research grant or textbook (Herman and Hilliam 2018). Even though there was a set agenda for exploring the various line items of Athena SWAN self-assessment processes, there were further cultural practices and considerations that required a focus on exploring unique regional characteristics beyond just regionality.

The University has been at the forefront of establishing flexible work and work-from-home arrangements for all staff, together with return-to-research funding schemes, which buy out teaching time to allow for the re-establishment of research undertakings, networks, and allies. Whilst these policies may have been identified, and a commitment to pay equity made, there is still work required in raising the voices within the sector to create discussion and positive disruption for change (Klein 2016). To continue to discuss and develop the culture of a values-driven University, clear leadership and systems and structural changes have been initiated to support and enable change, including undertaking leadership shadow exercises; running webinars for all staff on topics including gender equity, intersectionalities, and rights as staff; and promoting significant leadership and stewardship by engaging the senior leadership in unconscious bias training. Further investing in leadership development for women has also been key to dismantling gender inequity (Selzer et al. 2017; Silander et al. 2013), all of which sits within the context of a broad University equity and diversity 
framework. Engaging with the senior leadership and gaining their buy-in is integral to the enactment of University-wide policies and programs.

In line with the established understanding of gender equity and directly flowing from the auto-ethnographies was the notion of 'promotion relative to opportunity' (Winchester et al. 2006). This is an acknowledgement that merit should be based on that component of time engaged in the workplace and what is deemed to be relative opportunity for success. That is, no longer are 'male attributes' prized (for example, not taking leave for carer responsibilities), and assessment of merit does not concern itself with time in a position, but rather with contribution relative to the time formally engaged in the workplace. This principle of 'relative to opportunity' is included in the advancement, progression, and promotion policies for staff. While the University has provided new policy surrounding progression and promotion based on the concept of 'relative to opportunity', there are still more fundamental underlying issues that we need to address in the area of gender equity. One of these is the current lack of promotion opportunities for professional staff; however, the required resolution of this issue is noted.

The auto-ethnographies identified issues of job security and stability, and the impact of rolling contracts. Reaching permanency is desirable, but in reality, while ongoing casualisation of the higher education workforce creates opportunity for mobility, in some cases it impacts stability.

This perhaps is not unique to regional universities; however, the mobility to find other or complementary work is difficult. Whilst flexible work arrangements may overcome some barriers and provide work-life balance, the on-going requirement for travel between campuses is time consuming and needs to be planned to enable successful engagement with all, including those with carer responsibilities and disabilities. The use of effective technologies for communication and meetings, such as video conferences and Skype, are ways to overcome such barriers and are being used more and more within the University. This enables employees with carer responsibilities to still engage and make valuable contributions, as opposed to not attending a meeting at all. This style of alternate options for attendance at meetings is progressive and inclusive.

What becomes clear through the voices in this study is that regionality and the need to travel are additional complexities or intersectionalities that impact on a range of other opportunities. These in turn become barriers to progression and career trajectory, as well as networking opportunities. Despite this, the auto-ethnographies reveal solutions that can be considered in a policy framework to aid in overcoming the additional complexities, through further policy changes and better use of technologies and systems. Further work is progressing to understand and address issues of pay gaps at recruitment and impacts for sessional and part-time staff.

\section{Conclusions}

The barriers to women's achievement and career advancement in the higher education sector are well recognised and researched. This study has shown that workplace regionality and the need to travel are two additional key intersectionalities and barriers to success, in that they influence establishing meaningful workplace relations; building and maintaining networks and collaborations; attending key training and professional development; and career stability, promotion, and progression. Issues of geographical distance and the ability to maintain relationships and networks through technology is one way to overcome isolation and invisibility and increase engagement, however, more needs to occur to enable women to have the same aspirations and outcomes in their career trajectory in higher education. This study has identified that regardless of policy and leadership, there are still perceptions and real barriers that impact on career trajectories. The impact of leadership and enabling systems are key to unpacking inequalities and attaining genuine gender equity. A robust policy sense that reflects gender equity is vital. Engaging and establishing buy-in from leadership is fundamental to change, and in considering the impacts on women and striving for gender equity, systemic processes need to be explored, identified early, and enacted to strengthen equity of opportunity. 
This study as a reflective ethnographic study has impacted on the awareness and thinking of 'where to from now' regarding how the University approaches and delivers the Athena SWAN action plan. The 'voices' of the participants have provided rich insights and the catalyst for further reflection, discussion, and progression to genuine gender equity.

Author Contributions: Conceptualization, K.S., J.T. and C.T.; Methodology, C.T., J.T. and K.S.; Software, C.T.; Formal Analysis, J.T. and C.T.; Investigation, J.T. and C.T.; Writing-Original Draft Preparation, J.T. and C.T.; Writing-Review \& Editing, J.T., C.T. and K.S.; Project Administration, K.S. and J.T.

Funding: This research received no external funding.

Conflicts of Interest: The authors declare no conflict of interest.

\section{References}

Allan, Elizabeth J. 2008. Policy Discourses, Gender, and Education: Constructing Women's Status. New York: Routledge. Allen, Walter R., Marguerite Bonous-Hammarth, and Robert T. Teranishi. 2006. Higher Education in a Global Society Achieving Diversity, Equity and Excellence. Amsterdam: Elsevier JAI.

Alston, Margaret, and Wendy Bowles. 2018. Research for Social Workers: An Introduction to Methods, 4th ed. Sydney: Allen \& Unwin.

Blackmore, Jill. 2013. Student dis/satisfaction and academic dis/enchantment with edu-capitalism. ACCESS: Critical Perspectives on Communication, Cultural E Policy Studies 32: 27-34.

Boyatzis, Richard E. 1998. Transforming Qualitative Information: Thematic Analysis and Code Development. Thousand Oaks: Sage Publications.

Burkinshaw, Paula, and Kate White. 2017. Fixing the Women or Fixing Universities: Women in HE Leadership. Administrative Sciences 7: 30. [CrossRef]

David, Miriam E. 2015. Women and Gender Equality in Higher Education? Education Sciences 5: 10-25. [CrossRef]

Denshire, Sally. 2014. On auto-ethnography. Current Sociology 62: 831-50. [CrossRef]

Galanis, Petros. 2018. Data analysis in qualitative research: Thematic analysis. Archives of Hellenic Medicine 35: 416-21.

Griffin, Kimberly A., and Samuel D. Museus, eds. 2011. Using Mixed Methods to Study Intersectionality in Higher Education: New Directions in Institutional Research, Number 151. San Francisco: Jossey-Bass Inc Pub, p. 122.

Herman, Clem, and Rachel Hilliam. 2018. The Triple Whammy: Gendered Careers of Geographically Marginalised Academic STEM Women. International Journal of Gender, Science and Technology 10: 171-89.

Kim, Yong-Lyun. 2011. Gender Equity in Higher Education: Faculty Salaries, Career Development and Academic Services. Procedia-Social and Behavioral Sciences 29: 1274-78. [CrossRef]

Klein, Uta. 2016. Gender equality and diversity politics in higher education: Conflicts, challenges and requirements for collaboration. Women's Studies International Forum 54: 147-56. [CrossRef]

Morley, Louise. 2014. Lost leaders: Women in the global academy. Higher Education Research E Development 33: 114-28. [CrossRef]

Neale, Jenny, and Kate White. 2014. Australasian university management, gender and life course issues. Equality, Diversity and Inclusion: An International Journal 33: 384-95. [CrossRef]

Probert, Belinda. 1998. Gender Pay Equity in Australian Higher Education. Melbourne: National Tertiary Education Union.

Redmond, Petrea, Hannah Gutke, Linda Galligan, Angela Howard, and Tara Newman. 2017. Becoming a female leader in higher education: Investigations from a regional university. Gender and Education 29: 332-51. [CrossRef]

Selzer, Robin, Amy Howton, and Felicia Wallace. 2017. Rethinking Women's Leadership Development: Voices from the Trenches. Administrative Sciences 7: 18. [CrossRef]

Shaw, Ian, and Nick Gould. 2001a. Auto-Ethnography as Reflexive Inquiry: The Research Act as Self-Surveillance. London: SAGE Publications Ltd.

Shaw, Ian, and Nick Gould. 2001b. Qualitative Research in Social Work. London: SAGE.

Silander, Charlotte, Ulrika Haake, and Leif Lindberg. 2013. The Different Worlds of Academia: A Horizontal Analysis of Gender Equality in Swedish Higher Education. Higher Education: The International Journal of Higher Education and Educational Planning 66: 173-88. [CrossRef] 
The Associated Press. 2010. College Gender Gaps; “Gender Equity in Higher Education 2010”. (Brief article). Education Week 29: 5.

Tomaselli, Keyan. 2013. Visualizing Different Kinds of Writing: Auto-ethnography, Social Science. Visual Anthropology 26: 165-80. [CrossRef]

Wasserman, D. 2017. Barriers to gender equality in career advancement and leadership. European Psychiatry 41: S54. [CrossRef]

Winchester, Hilary, Shard Lorenzo, Lyn Browning, and Colleen Chesterman. 2006. Academic women's promotions in Australian universities. Employee Relations 28: 505-22. [CrossRef]

(C) 2019 by the authors. Licensee MDPI, Basel, Switzerland. This article is an open access article distributed under the terms and conditions of the Creative Commons Attribution (CC BY) license (http://creativecommons.org/licenses/by/4.0/). 